\title{
Design and Development of Online Dog Diseases Diagnosing System
}

\author{
Munirah M. Y., Suriawati S., and Teresa P. P.
}

\begin{abstract}
There are varied common diseases that can infect dogs. If dog had been infected by certain diseases, some of the guardian will try to treat their infected dog on their own. This happen for those who are breeding dog, yet have no time to take the dog to meet veterinary when their dogs is unwell. However, sometimes this treatment was not suitable with that particular problem and can make it become worse. Thus in this paper, our objective is to develop a set rules that focus on diagnosing seven common dogs diseases which are Distemper, leptospirosis, Glaucoma, Colitis, Kennel Cough, Parvo Virus and Jaundice. In the near future, we will develop an Online Dogs Diseases Diagnosing System that used the concept of expert system to user in detecting the diseases, provide treatment and useful suggestion.
\end{abstract}

Index Terms-Expert system, forward chaining, veterinary, dogs' diseases.

\section{INTRODUCTION}

Dog had been acknowledged as men best friends, and most human keep pets for its companionship [1]. Some owner keeps dogs because they can share similar social organizations and communication system with humans than other animals. Whatever the reason for keeping these dogs, as an owner, they will care and provide proper space, diet and health care for their pets [2]. Some owner, in handling their dogs healthcare tend to assume that certain diseases are mild, and they are not seeking the veterinary help in diagnosing the diseases. Some of them will try to treat these infected dogs on their own. However, sometimes this treatment was not suitable with that particular problem and can make it become worse. This cause disturbance for dogs daily habitual and their behavior may be different either being a bit fierce or tired and inactive. Knowing about common dog diseases and being aware of appropriate treatment can better help the owner in taking care of their dogs. Therefore, one main issue in this paper is to ensure that the diseases can be detected on early stage and with this expert system it will assist owners in detecting the dog diseases and provide treatment suggestion.

In this research, we place our focus on common dog diseases. The main objective of this research is to develop

Manuscript received August 25, 2014; revised July 14, 2015.

Munirah M. Y. is with the Software Engineering Department of University of Tun Hussein Onn Malaysia, Malaysia (e-mail: munirah@uthm.edu.my).

Suriawati S. is with the Multimedia Department of University of Tun Hussein Onn Malaysia, Malaysia (e-mail: suriati@uthm.edu.my).

Teresa P. P. is with the Faculty of Science Computer and Information Technology, University Tun Tun Hussein Onn Malaysia, Malaysia (e-mail: tp_teresa@hotmail.com). expert system for diagnosing the common dog diseases in near future. Currently, at this point, from the data analysis, the rules have been developed. There are seven types of common diseases have been identified for this research; Distemper, leptospirosis, Glaucoma, Colitis, Kennel Cough, Parvo Virus and Jaundice. As mention before, the mistake in diagnosing these dog diseases can lead to more serious infection. Therefore, this research is important for user with the purpose to assist them in detecting the diseases based on the given symptoms.

Section II provides the related works in expert system, while Section III briefly discusses the methodology. Section IV discusses on design and development of the system and Section $\mathrm{V}$ discuss on expected result and output, while the last section draws our conclusions.

\section{RELATED WORK}

Artificial Intelligence (AI) is the area of computer science focusing on creating machines that can engage on behaviours that humans consider intelligent. It involves studying the human thinking processes and deals with representing and duplicating these processes through machines. Expert Systems (ES) is one of the artificial intelligence fields, and were developed by the AI community in the mid-1960s. According to Darlington [3], an expert system is a program that attempts to mimic human expertise by applying inference methods to a specific body of knowledge. Turban et.al defined expert system as an intelligent computer program that mimic human experts' problem solving capabilities [4].

One of the needs of expert systems in medical is for technical information transfer. Using traditional methods, expert help identified diseases with symptoms shown and transfer the information or result individually to the patients. Using expert systems, it generates results and appropriate advice too based on its knowledge base and reasoning mechanism. The knowledge acquisition process in developing expert systems facilitates in integration knowledge and experiences gathered from various experts. Besides, images can be integrated with the knowledge to make system more user friendly and help in giving more understanding in describing the symptoms.

Rapid increase of Internet application too play big role in expert system growth [5]. The early applications of expert systems were standalone, based on mainframe, AI workstations or PC platforms and from this it moved to web based experts system. It revolutionized information technology and creating opportunities for developing distributed applications and it enhancing traditional expert systems. 
Expert systems have been a highly active research field in the past few years as a mean of conducting medical diagnosis and recommending treatment [6]. There are many expert systems that were developed to diagnose human diseases, prescribing drugs or provide suggestive treatment [7]-[11]; but it is ongoing for animal diseases diagnosis.

Li et al. [5] research is on developing a web based intelligent diagnosis for fish diseases. This been a concern as diagnosing fish diseases is a complicated process and requires high level of expertise. This system diagnoses 126 types of diseases among nine species of primary freshwater fish. The knowledge base consist of all the rules for the fish diseases with two sections a symptom pattern and the diseases. Fu et al. [12] developed an expert system name Pig-Vet to diagnose pig diseases. The system can diagnose 54 different types of pig diseases and symptoms. This system is needed to help pig farmers to diagnose, treat and prevent pig disease timely and effectively because of the insufficient of pig vets.

In this study, Online Dog Diseases Diagnosing System will provide diagnosis module and treatment module as main modules. In addition this system will be designed as web based platform to deliver system information to their respective online user.

\section{Methodology}

In this research, Online Dogs Diseases Diagnosing System was developed based on Knowledge Engineering (KE) methodology (Fig. 1). This methodology is suitable for this project because it support many types of knowledge based system and consist of special translator that able to control forward chaining mechanism and back forward chaining mechanism.

This methodology consists six phases [13], however only five phases applied in this research which is problem assessment, data and knowledge acquisition, development of a prototype system, development of a complete system, evaluation and revision of the system. Integration and maintenance of system phase which is the final phase was not applied because this project only involved in the process of system development and those maintenance tasks are depend on organization that uses the system.

In problem assessment phase, research on dog diseases in general had been done. Besides, other step is to analysis and determines the problems that involve in manual diagnosis method on dog diseases. This is because it can help in determining the objective of project, target user and scopes of system. The main objective in data and knowledge acquisition phase is to collect all the information and treatment's knowledge of dogs' diseases. This information about the diseases such as symptoms, treatment, advices had been collected from various sources. However, main sources were gathered via interview method from one of the expert. The purpose of this interview is to gather knowledge from reliable sources that have experience in diagnosing children skin problem and diseases. Besides, it will help in understand more about the diseases and get direct feedback on other gathered information on the symptoms and treatments. Set of rules based on the symptoms and diseases will be stored in knowledge based and retrieve by forward chaining technique.

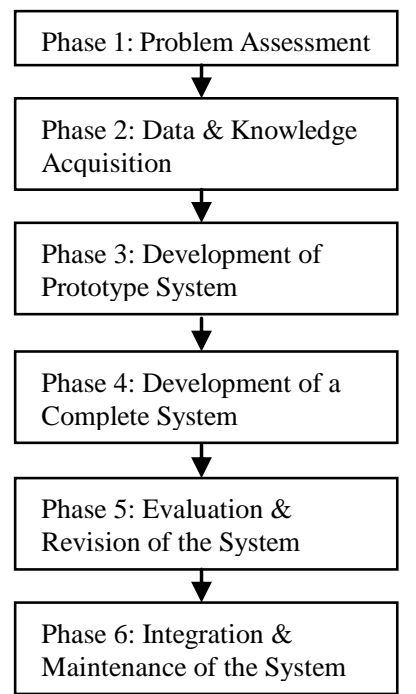

Fig. 1. Process of knowledge engineering methodology [13].

Before developing the prototype system, the system will be represented by system architecture shown in Fig. 2 and context diagram shown in Fig. 3. Suitable tools are selected for developing purposed. The prototype need to be developed to get feedback on the expert system prototype from user thus can fix error, add and enhance their functionality when developing the real expert system. Prototype system development helps knowledge engineer ensure the process of developing complete expert system will be smooth without much hassle and error.

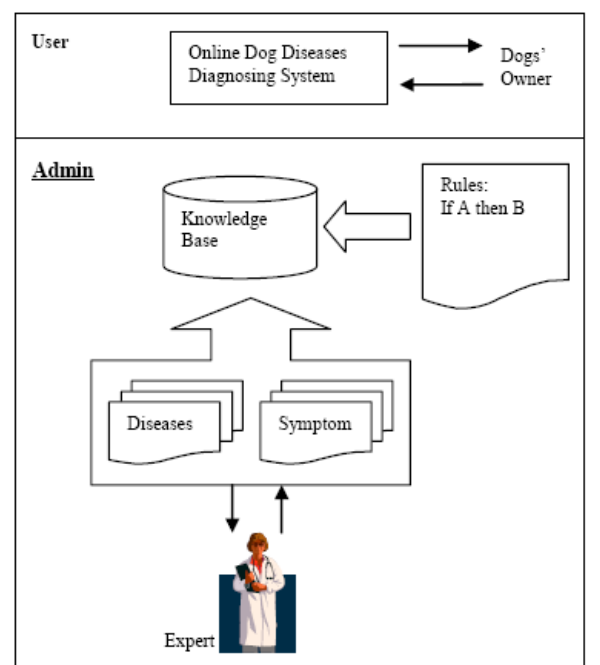

Fig. 2. System architecture for online dog diseases diagnosing system.

Complete system will be developed during development of a complete system phase. The main work of this phase is adding data and knowledge into database of system. User interface will be developed to deliver information to user. The user interface will be design as user friendly and easy for user to obtain information from system. As the project proceeds, new data and knowledge will be collected and added to the system by having interview session with expert. The capability of the system improves and the prototype will gradually evolve into a final system.

In evaluation and revision phase, a complete system of Online Dog Diseases Diagnosing System is tested and evaluated against the performance criteria to ensure that the 
system can function well. This test is important to ensure the system will fulfil the development objective and requirement for end user. Therefore, in next stage, when all of the phases complete, the output will be a complete Online Dog Diseases Diagnosing System.

\section{SYSTEM DESIGN AND DEVELOPMENT}

Design phase will produce a true sketch of the system. This section will focus on architecture and context diagram design of the system. The architecture design of Online Dog Skin Diseases Diagnosing System consists of a database known as knowledge base with rules of symptoms and diseases and the user interfaces. Its general structure is showed in Fig. 2.

The system administrator is an expert where in this research is a veterinary that we have interviewed before, while, the user is either dogs' owner or regular user. From expert we obtain the information such as type of diseases and the symptom disease. The rules will be generated from this information. All the generated rules store in knowledge base. Then the user will input the symptom and the system will retrieve the related rules and post the suggested solution. Conventional experts systems were developed for stand-alone computers but with the rapid development of the Internet, more web-based expert systems are beginning to emerge. Thus, this system was developed using a mixture of Internet based programming and SQL programming languages. PHP and Java Script were used in the programming while Dreamweaver CS4 used as a platform for interfaces design. MySQL was used as database and WAMP for web server. The database includes symptoms, diseases, treatments, photos, questions and some general information about the diseases.

System functionality design for Online Dog Diseases Diagnosing System in this paper is presented in context diagram shown in Fig. 3. Context Diagram shows the entire system as a single process, connected only to the external entities. The context diagram is closely associated with the scope section of the system.

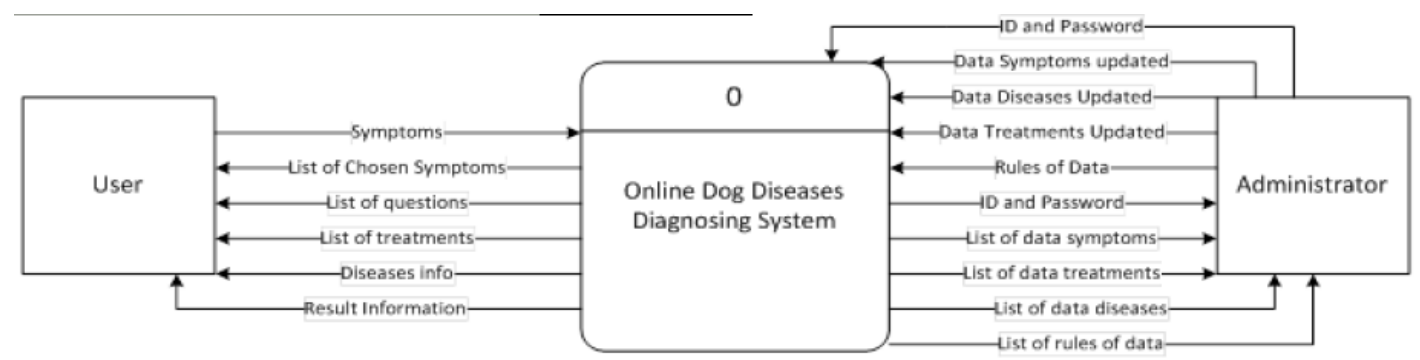

Fig. 3. Context diagram for online dog diseases diagnosing system.

\section{KNOWLEDGE REPRENSENTATION}

The Online Dog Diseases Diagnosing System knowledge based was developed using rules. An expert system based on rules which are the individual steps in a decision making process. The set of rules used IF / THEN structure where the information contained in the IF related to other information contained in the THEN part. It explains on how or why a decision was made. Knowledge representation helps in creating the rules. Knowledge and facts in the knowledge base will be translated into form of knowledge representation. There are eleven rules based on seven types of common dog diseases, as shown in Table I. The diseases are Distemper, Leptospirosis, Glaucoma, Colitis, Kennel Cough, Parvo Virus and Jaundice.

TABLE I: RULES BASED ON THE SYMPTOMS' DISEASES

\begin{tabular}{|l|l|l|}
\hline Rule & Diseases & Symptoms \\
\hline 1 & Distemper & IF Fever \\
& & AND Normal fever \\
& & AND Husky cough \\
& & AND Has seizure \\
& & AND Runny nose \\
& & AND Normal situation \\
& & THEN Distemper \\
\hline 2 & ParvoVirus & IF Fever \\
& & AND Normal fever \\
& & AND No cough \\
& & AND Has diarrhea \\
& & AND Bloody diarrhea \\
& & AND No feel vomitting \\
\hline
\end{tabular}

\begin{tabular}{|c|c|c|}
\hline & & THEN ParvoVirus \\
\hline 3 & & $\begin{array}{l}\text { IF Has diarrhea } \\
\text { AND Normal diarrhea } \\
\text { AND Has jaundice } \\
\text { AND Discomfort } \\
\text { THEN Parvo Virus }\end{array}$ \\
\hline 4 & Infectious Hepatitis & $\begin{array}{l}\text { IF Fever } \\
\text { AND High Fever } \\
\text { AND Eye inflammation } \\
\text { AND Has seizure } \\
\text { AND Normal diarrhea } \\
\text { AND Distention } \\
\text { THEN Infectious Hepatitis }\end{array}$ \\
\hline 5 & Leptospirosis & $\begin{array}{l}\text { IF Fever } \\
\text { AND High fever } \\
\text { AND Normal situation } \\
\text { AND Less urine } \\
\text { AND Dark or brown urine } \\
\text { AND Bright yellow urine } \\
\text { THEN Leptospirosis }\end{array}$ \\
\hline 6 & & $\begin{array}{l}\text { IF Fever } \\
\text { AND Normal fever } \\
\text { AND No cough } \\
\text { AND No diarrhea } \\
\text { AND Has jaundice } \\
\text { AND Abdomen feel normal } \\
\text { AND Less urine } \\
\text { AND Dark or brown urine } \\
\text { THEN Leptospisosis }\end{array}$ \\
\hline 7 & Lyme's Disease & $\begin{array}{l}\text { IF Fever } \\
\text { AND High fever } \\
\text { AND Normal eye } \\
\text { AND Normal urine } \\
\text { AND Look like dehydrated }\end{array}$ \\
\hline
\end{tabular}




\begin{tabular}{|c|c|c|}
\hline & & $\begin{array}{l}\text { AND Has muscle pain } \\
\text { AND Limping or lameness } \\
\text { THEN Lyme's Disease }\end{array}$ \\
\hline 8 & Rabies & $\begin{array}{l}\text { IF Fever } \\
\text { AND Has chew itself } \\
\text { AND Foaming } \\
\text { AND Suddenly attack people } \\
\text { THEN Rabies }\end{array}$ \\
\hline 9 & & $\begin{array}{l}\text { IF Fever } \\
\text { AND Normal fever } \\
\text { AND Normal cough } \\
\text { AND Has chew itself } \\
\text { AND Foaming } \\
\text { AND Suddenly attack people } \\
\text { THEN Rabies }\end{array}$ \\
\hline 10 & Colitis & $\begin{array}{l}\text { IF No fever } \\
\text { AND Normal situation } \\
\text { AND Normal urine } \\
\text { AND No look like dehydrated } \\
\text { AND No muscle } \\
\text { AND Normal walking } \\
\text { AND Bloody diarrhea } \\
\text { AND Feel vomitting } \\
\text { THEN Colitis }\end{array}$ \\
\hline 11 & Kernel Cough & $\begin{array}{l}\text { IF Fever } \\
\text { AND Normal Fever } \\
\text { AND Dry cough } \\
\text { THEN Kernel Cough }\end{array}$ \\
\hline
\end{tabular}

This system will be developed based on forward chaining inference process. Forward chaining works from the facts to a conclusion. In this system, facts are provided to the system when user answering questions display on user interfaces. Then, inference processes automatically matches facts against patterns and determine which rules are applicable. The system then will produce conclusions of the diagnosis and suggest suitable treatment methods.

\section{EXPEXTED RESULT AND OUTPUT}

The expected result of this study is to produce a diagnosis system which be able to help user recognize dogs' diseases and provide suitable advises or treatments. Users only need to answer few questions by selecting an answer and the system will generate output results. Besides, administrator can login into system and manage the information in the Online Dog Diseases Diagnosing System.

\section{CONCLUSION}

In this paper, a set of rules has been developed for helping user diagnosing seven common dogs' diseases. In future, completed system will be developed and help user diagnosing and determining skin diseases and give suggestive treatment more faster and convenient way by using online system. Besides, it also can provide some useful information about skin diseases to users. We also hope it will be an alternative for user to obtain related information on dogs' diseases, symptoms and its treatment.

\section{ACKNOWLEDGEMENT}

The authors would like to thanks Universiti Tun Hussein Onn Malaysia for the financial support.

\section{REFERENCES}

[1] K. Wilks, "When dogs are man's best friend - The health benefits of companion animals in the modern society," presented at Urban Animal Management Conference, 1999.

[2] D. Rice. (March 20, 2014). Common dog diseases and health problems 4-H Companion Animal Health. [Online]. Available: https://www.extension.purdue.edu/extmedia/4H/4-H-852-W.pdf.

[3] K. Darlington, The Essence of Expert Systems, Prentice Hall, 2000.

[4] E. Turban, J. E. Aronson, and T. P. Liang, Decision Support Systems and Intelligent Systems, Pearson Prentice Hall, 2005.

[5] D. Li, Z. Fu, and Y. Duan, "Fish-expert: A web-based expert system for fish disease diagnosis," Expert Systems with Applications, vol. 23, pp. 311-320, 2002.

[6] L. G. Kabari and F. S. Bakpo, "Diagnosing skin diseases using an artificial neural network," in Proc. the 2nd International Conference on Adaptive Science \& Technology, IEEE, 2009, pp. 187-191.

[7] S. Ismail, A. Novrus, and U. S. Ibrahim, "A fuzzy expert system design for diagnosis of prostate cancer," in Proc. International Conference on Computer Systems and Technologies, 2003.

[8] J. C. Chen, T. S. Liu, C. S. Weng, and J. S. Heh, "An expert system of coronary artery disease in chinese and western medicine," in Proc. Conference the Japan Society of Medical Electronics \& Biological Engineering, 2005.

[9] S. K. Patra, D. P. Sahu, and I. Mandal, "An expert system for diagnosis of human diseases," International Journal of Computer Applications, vol. 1, no. 13, 2010.

[10] S. S. A. Naser and A. Z. A. Ola, "An expert system for diagnosing eye diseases using CLIPS," International Journal of Computer Applications, vol. 1, no. 13, 2010.

[11] D. Zeldis and S. Prescott, "Fish disease diagnosis program - Problems and some solutions" Aquacultural Engineering, vol. 23, no. 1-3, pp. 3-11, 2000.

[12] Z. Fu, F. Xu, Z. Yun, and X. Zhang, "Pig-vet: A web-based expert system for pig disease diagnosis," Expert Systems with Applications, vol. 29, pp. 93-103, 2005.

[13] M. Negnevitsky, Artificial Intelligence: A Guide to Intelligent Systems, 2nd ed., England: Pearson Education, 2005.

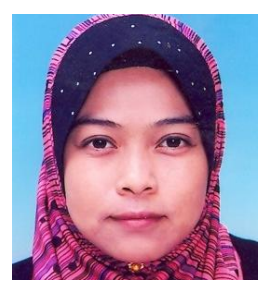

Munirah M. Yusof is a lecturer in Software Engineering Department of University of Tun Hussein Onn Malaysia. She became a member of IACSIT. Her research interest including intelligent system, case based reasoning and soft computing.

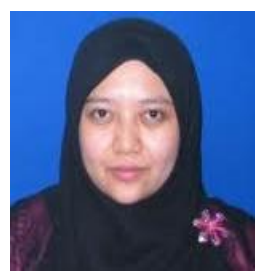

Suriawati S. is a lecturer in Multimedia Department of University of Tun Hussein Onn Malaysia. Her research interests include software requirements engineering, soft computing and industrial computing.

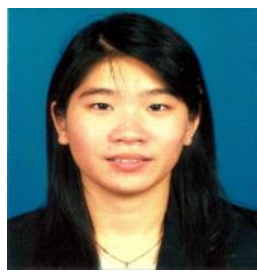

Teresa P. P. is a student in Faculty of Science Computer \& Information Technology, University Tun Tun Hussein Onn Malaysia. 